(i.;.

\title{
RACORO Data Guide
}

\section{Revision 1}

A Vogelmann

May 2012

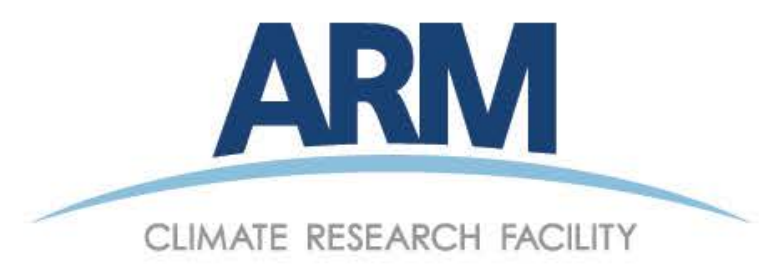




\section{DISCLAIMER}

This report was prepared as an account of work sponsored by the U.S. Government. Neither the United States nor any agency thereof, nor any of their employees, makes any warranty, express or implied, or assumes any legal liability or responsibility for the accuracy, completeness, or usefulness of any information, apparatus, product, or process disclosed, or represents that its use would not infringe privately owned rights. Reference herein to any specific commercial product, process, or service by trade name, trademark, manufacturer, or otherwise, does not necessarily constitute or imply its endorsement, recommendation, or favoring by the U.S. Government or any agency thereof. The views and opinions of authors expressed herein do not necessarily state or reflect those of the U.S. Government or any agency thereof. 


\section{RACORO Data Guide}

\section{Revision 1}

A Vogelmann

May 2012

Work supported by the U.S. Department of Energy, Office of Science, Office of Biological and Environmental Research 


\section{Summary}

This document provides an overview to the five-month RACORO Campaign (Vogelmann et al. 2012).

Version 2 of this guide (released March 2012) updates: the preferred instruments for cloud measurements and data set availability and provides additional notes/discoveries on data usage. Updated data availability is summarized in Table 2 .

There are many details in such an extensive program that this document cannot capture; therefore, it should be thought of as a guide for acquainting yourself with the program and you are encouraged to contact the members involved.

In particular, users of the data are strongly urged to contact instrument principal investigators (PIs) about use of the data. Further, it is highly recommended that studies using the data be done in collaboration with the instrument PIs, since they are in the best position to provide insights and or caveats associated with the data that should be considered.

For other additional information, please contact a member of the RACORO Steering Committee:

Andy Vogelmann ogelmann@bnl.gov

Jennifer Comstock Jennifer.Comstock@pnnl.gov

Graham Feingold $\quad$ Graham.Feingold@noaa.gov

Chuck Long hㅡ‥Long@pnnl.gov

Greg McFarquhar $\quad$ mcfarq@atmos.uiuc.edu

John Ogren $\quad$ John.A.Ogren@noaa.gov

Dave Turner $\quad$ Dave.Turner@noaa.gov

Please send document corrections/comments to Andy Vogelmann (vogelmann@bnl.gov) 


\section{Acknowledgments}

A campaign of this scope would not have been possible were it not for the remarkable skill and dedication sustained by a host of people, who are gratefully acknowledged here.

$-A M V$

\section{Steering Committee}

Jennifer Comstock, Graham Feingold, Chuck Long, Greg McFarquhar, John Ogren, and Dave Turner

\section{AAF Technical and Mission Science Office}

Debbie Ronfeld, John Hubbe, Jason Tomlinson, and Beat Schmid

CIRPAS Aircraft Operations

Haf Jonsson, Greg Cooper, Mike Hubbell, and Chris McGuire

Zivko Aeronautics

Jesse Barge, Dave McSwaggan, and Dan Bierly

\section{Instrument PIs}

Anthony Bucholtz, Don Collins, Glenn Diskin, Hermann Gerber, Haf Jonsson, Paul Lawson, Chuck Long, and Roy Woods

\section{SGP Operations and Forecasting}

Daniel Hartsock, Justin Monroe, and Pete Lamb

Web and Media

Lynne Roeder, Sherman Beus, Rolanda Jundt, and Tonya Martin

\section{IOP Share}

Chaomei Lo, Raymond McCord, Dave Still, and Jennifer Comstock

\section{Summary Files}

Jennifer Comstock, Chaomei Lo, and the instrument PIs listed above

\section{IOP Archive}

Alice Cialella 


\section{Contents}

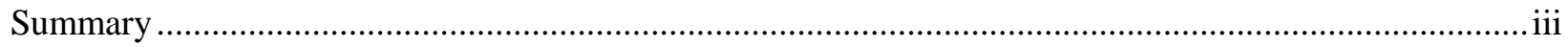

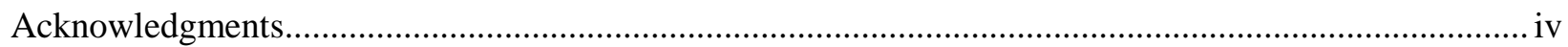

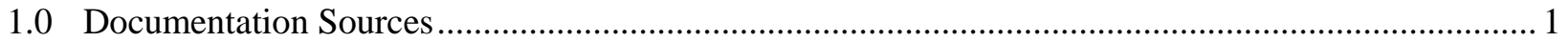

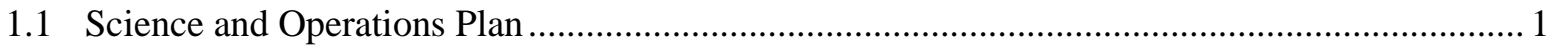

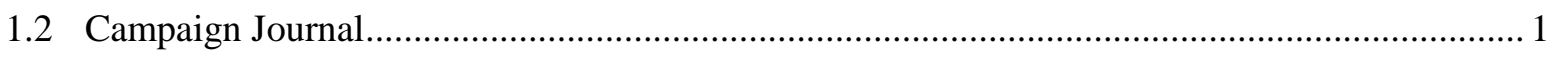

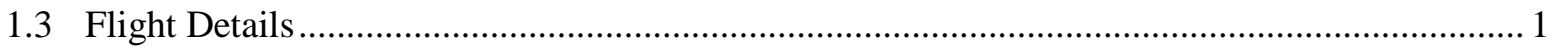

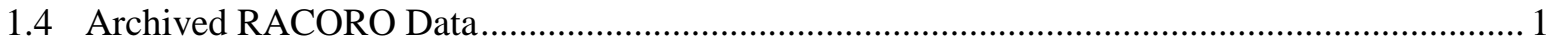

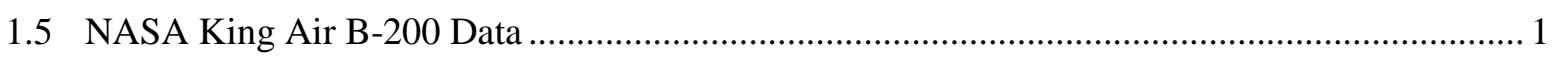

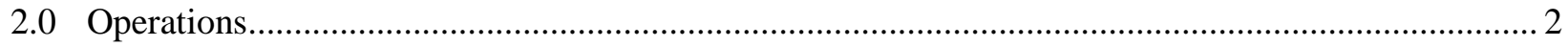

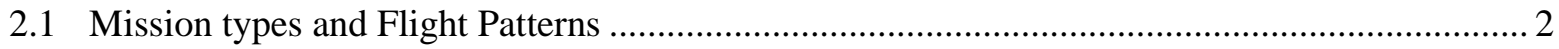

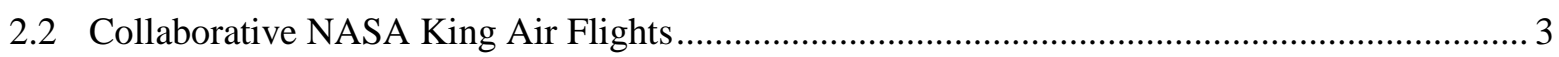

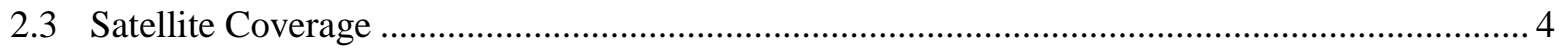

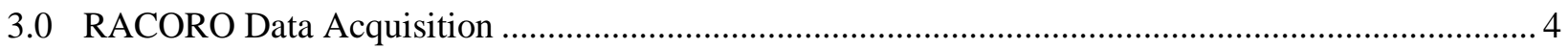

3.1 Primary instruments, Measurements, and PIs ...................................................................... 4

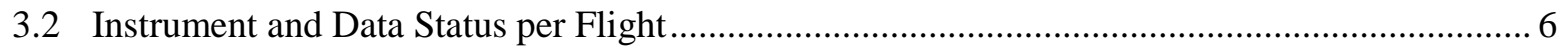

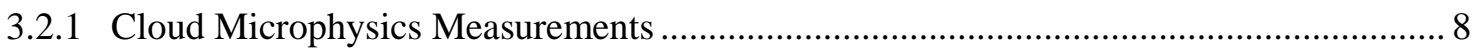

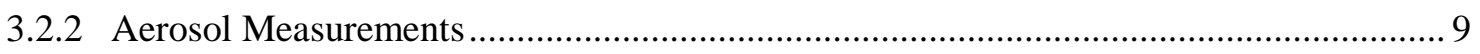

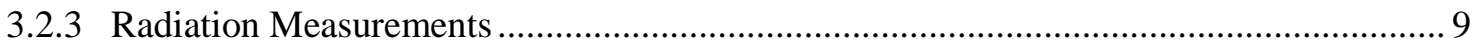

3.2.4 Atmospheric State Measurements ........................................................................... 11

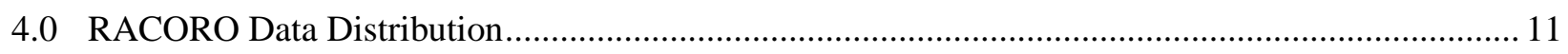

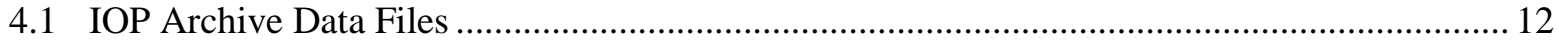

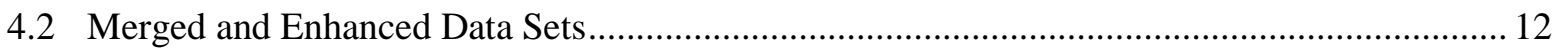

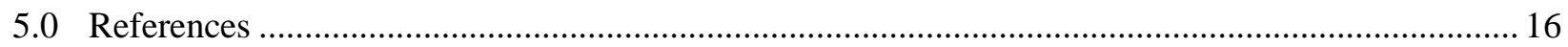

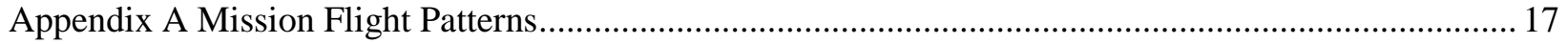

Appendix A Mission Flight Patterns............................................................................................ A.

Appendix B EOS Satellite Overpasses During RACORO …............................................................. 


\section{Tables}

Table 1. RACORO Instrumentation. The symbol $\uparrow$ means upward-looking and $\downarrow$ means

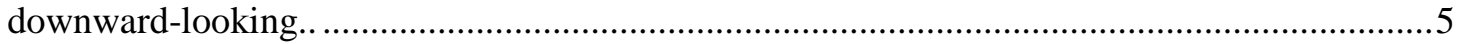

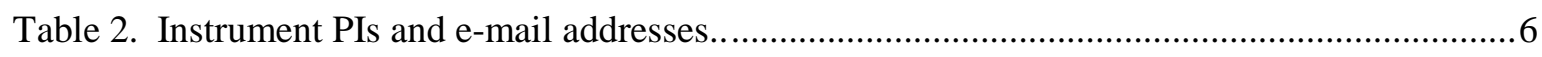

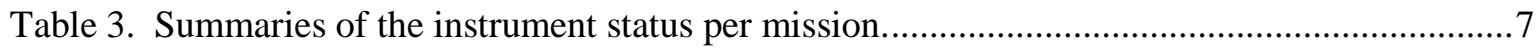

Table 4. Contents of data sets listed on the RACORO IOP Archive..............................................14 


\subsection{Documentation Sources}

RACORO is described at http://campaign.arm.gov/racoro/ and on links therein. Please use the Vogelmann et al. (2012) BAMS paper as the reference for the campaign.

\subsection{Science and Operations Plan}

(http://www.arm.gov/publications/programdocs/doe-sc-arm-0806.pdf): Articulates the types of science questions to be addressed and the anticipated instrument payload and flight measurement strategies used to obtain the needed data. (Where details are different from this document, this document supersedes the Science and Operations Plan.)

\subsection{Campaign Journal}

(http://campaign.arm.gov/racoro/journal): Summarizes each mission, providing a brief summary, a flight map, downloadable flight images, and quicklooks from the SGP surface instrumentation.

\subsection{Flight Details}

(http://campaign.arm.gov/racoro/flights): Provides more detailed information for each flight that includes pilot notes, a KML file of the flight, downloadable flight images, weather maps, instrument status, and quicklooks from the aircraft measurements and SGP surface instrumentation.

\subsection{Archived RACORO Data}

(http://www.arm.gov/campaigns/aaf2009racoro\#data): The data archive includes all measurements (described more in Section 4 of this document) as well as merged products and atmospheric forcing data needed for model simulations.

Note: Be sure to read the Instrument readme files.

\subsection{NASA King Air B-200 Data}

The NASA King Air B-200 flew coordinated patterns with the RACORO team from 3 June to 26 June. The King Air carried the High Spectral Resolution Lidar (HSRL; Hair et al. 2008, Rogers et al. 2009) and the Research Scanning Polarimeter (RSP; Cairns et al. 2009).

King Air flight summaries are available from ftp://racoro:\&thinCLOWD2009@mountkoya.larc.nasa.gov/RACORO_Scorecard.xls

HSRL quicklooks are available under "Flight Details” and from the directory of the aforementioned link. HSRL Data: Available from ftp://racoro:\&thinCLOWD2009@mountkoya.larc.nasa.gov/ 


\section{Contacts}

Richard Ferrare (richard.a.ferrare@nasa.gov, 757-864-9443)

Chris Hostetler (chris.a.hostetler@nasa.gov, 757-864-5373) and/or

John Hair (johnathan.w.hair@nasa.gov, 757-864-1406).

RSP Data: Available from ftp://ftp.giss.nasa.gov/pub/rsp/RACORO. Useful information about the RSP (absorption parameterizations for the SWIR bands and ozone and $\mathrm{NO}_{2}$ absorption coefficients for the VNIR) are at ftp://ftp.giss.nasa.gov/pub/rsp/RSP_Utilities together with an IDL read/plot program the program that writes the netCDF files and the RSP spectral responses.

\section{Primary Point of Contact}

Brian Cairns (brian.cairns-1@nasa.gov; bc25@columbia.edu, 212-678-5625)

\section{Secondary Points of Contact:}

Mikhail Alexandrov (malexandrov@giss.nasa.gov, 212-678-5548)

Matteo Ottaviani (mottaviani@giss.nasa.gov, 212-678-5643)

\subsection{Operations}

RACORO operations ran from 24 January to 29 June 2009. From 24 January to 27 May, flights were based out of Guthrie, Oklahoma (about 50 miles south of ARM's Southern Great Plains (SGP) site); from 30 May to 29 June flights were based out of Ponca City, Oklahoma (about 20 miles northeast of SGP). The latter location facilitated flight coordination with the NASA King Air from 3 June to 26 June. RACORO flights lasted between three to five hours and occurred as conditions allowed (determined by members of the steering committee, AAF representatives, forecasters, and pilots).

\subsection{Mission types and Flight Patterns}

The highest priority was to sample boundary layer cloud fields over the SGP facility. We sampled clouds away from the SGP if airspace restrictions prevented us from operating within cloud over the SGP, or if clouds formed away from the SGP (but within our permitted flight radius). In the case of airspace restrictions, we often operated just east of the SGP where there were fewer restrictions.

Clear-sky missions were also flown to obtain data that supported RACORO analyses. These flights were used for:

- aircraft radiometer characterization

- aerosol characterization (especially relative to the SGP surface measurements)

- surface albedo mapping around the SGP 
- determining the boundary layer turbulence structure (for validation of a retrieval technique using the SGP Raman lidar).

Given the lack of clouds in the early months of the campaign, approximately half of the flights were cloud flights. When possible, flights were flown during Terra or Aqua daytime overpasses.

The default flight patterns are listed below and described in Appendix A.

1. Cloudy-Sky Patterns:
a. Cloud Triangles Flight Plan
b. Cloud Missed Approaches Flight Plan
c. Cloud Out-and-Back Flight Plan

2. Other Patterns:
a. Surface Albedo Flight Plans
b. Turbulence Flight Plan
c. Radiometer Tilt Characterization Flight Plan
d. Aerosol Triangles Flight Plan
e. Aerosol Long-Leg Variability Characterization Flight Plan

These names are used in the headers for the Campaign Journal and Flight Details to identify the mission type. The "other" patterns were flown when boundary-layer clouds were not present. The radiometer tilt characterization pattern (f) required clear skies, but the other patterns could be flown with clear skies or when upper-level clouds were present.

Note that the patterns were modified by the pilots when the conditions warranted (i.e., to improve the cloud catch but still maintain statistical sampling of the cloud field). Therefore, the pilot notes within the Flight Details should be consulted to know the exact flight pattern flown.

\subsection{Collaborative NASA King Air Flights}

As mentioned earlier, the NASA King Air B-200 carried the HSRL and the RSP and flew coordinated patterns with the RACORO team from 3 June to 26 June. The periods when the King Air flew overhead of the CIRPAS Twin Otter are summarized at:

ftp://racoro:\&thinCLOWD2009@mountkoya.larc.nasa.gov/RACORO_Scorecard.xls

In Appendix A, note that ordering of the legs used in the "Cloud Triangles Flight Pattern" were modified slightly so that spirals and upper cloud sampling occurred when the King Air was on station. (See Section 1.E for King Air contacts.) 


\subsection{Satellite Coverage}

GOES visible imagery of the Oklahoma region was archived by Owen Cooper (owen.r.cooper@noaa.gov; see the IOP archive).

We also preferred flying at times that were at or close to EOS satellite overpasses (when the satellite viewing conditions were favorable) so that the satellite retrievals could provide an overview of the conditions being sampled. The closest daytime overpasses (in GMT) were approximately 17:30 for Terra, 19:30 for Aqua, and 20:00 for CloudSat/CALIPSO. During the RACORO period, arrangements also were made by A. Marshak (NASA) for MISR Local Mode data to be acquired on Terra flight overpass paths \#28 and 29 (path \#27 was committed to another region). A table of overpass times during RACORO flights is given in Appendix B.

\subsection{RACORO Data Acquisition}

\subsection{Primary instruments, Measurements, and PIs}

The RACORO payload was designed to be cross-disciplinary and included measurements of the cloud microphysics, radiation, aerosol, and atmospheric state. In some cases, we did not have an instrument sufficiently robust for long-term operations that had the desired (fast) response (e.g., $10 \mathrm{~Hz}$ ) for sampling the often broken or tenuous boundary-layer clouds. In these cases, we paired a slow, accurate measurement with a fast, precise measurement (see discussion in the Science and Operations Plan), which also provided instrument redundancy.

The instruments and measurements are summarized in Table 3.1, along with any further specifications or comments; the instrument PIs are listed in Table 1. In addition to the measurements listed, aircraft flight parameters (e.g., lat/lon, altitude, heading, pitch and roll angles, etc.) were recorded at between 10 and $100 \mathrm{~Hz}$. All data are time-synchronized with the CIRPAS cabin computer.

As for the instrument location/mounting on the CIRPAS Twin Otter, as is common practice, cloud and atmospheric state measurements were made from probes installed on the fuselage or from pods suspended from the aircraft wings. Additionally:

- The CIRPAS aerosol inlet was mounted about $1 \mathrm{~m}$ above the upper nose surface to minimize air flow distortion around the fuselage. The transmission efficiency of the CIRPAS aerosol inlet is discussed in Hegg et al. (2005). In-cloud measurements of CCN and CN (from the CPCs) should be valid in cloud, since cloud making its way down the inlet probably evaporates in the nose diffuser where there is a degree and a half of ram heating (12-15\% decrease in $\mathrm{RH})$.

- The radiometers were mounted on posts that extend away from the fuselage, thereby reducing the likelihood of obstacles contaminating the measurements of the instruments that have a hemispheric field of view. In lieu of a stabilized platform, the zenith-viewing shortwave irradiances were corrected for aircraft attitude (pitch and roll) via the method of Long et al. (2010). (See additional information in Section 4.B.) 
Table 1. RACORO Instrumentation. The symbol $\uparrow$ means upward-looking and $\downarrow$ means downward-looking. The measurement rates given (e.g., $10 \mathrm{~Hz}$ ) represent the upper limits possible; the data might be available at lower rates (see Section 4).

\begin{tabular}{|c|c|c|c|}
\hline CATEGORY & MEASUREMENT & INSTRUMENT & SPECIFICATIONS ANDIOR COMMENTS \\
\hline \multirow[t]{7}{*}{$\begin{array}{l}\text { CLOUD } \\
\text { MICROPHYSICS }\end{array}$} & \multirow[t]{2}{*}{$\begin{array}{l}\text { Liquid-Water } \\
\text { Content (LWC) }\end{array}$} & Particle Volume Monitor-100A (Gerber Probe) & $\begin{array}{l}\text { LWC and Effective radius; } 100 \mathrm{~Hz} \text { reported at } 10 \mathrm{~Hz} \\
\text { LWC sensitivity roll off starts } \sim 30 \mu \mathrm{m}\end{array}$ \\
\hline & & SEA LWC Probe (WCM-2000, LWC only) & $10 \mathrm{~Hz}$ \\
\hline & \multirow{4}{*}{$\begin{array}{l}\text { Drop Size } \\
\text { Distribution }\end{array}$} & Forward Scattering Spectrometer Probe-100 (FSSP) & $2-30 \mu \mathrm{m}$ at $1 \mathrm{~Hz}$ \\
\hline & & Cloud, Aerosol Precipitation Spectrometer (CAPS) & $\begin{array}{c}0.5-1,550 \mu \mathrm{m} \text {; Consists of a CAS }(0.5-50 \mu \mathrm{m}) \text { at } 10 \mathrm{~Hz} \text { and } \\
\text { a 1D CIP }(25-1,550 \mu \mathrm{m}) \text { at } 1 \mathrm{~Hz}\end{array}$ \\
\hline & & 2D Cloud Imaging Probe (2D CIP) & $50-1,600 \mu \mathrm{m}$, at $1 \mathrm{~Hz}$ \\
\hline & & 2D Stereo Probe (2D-S) & $10-1,280 \mu \mathrm{m}, 10 \mathrm{~Hz}$ reported at $1 \mathrm{~Hz}$ \\
\hline & Cloud Extinction & Cloud Integrating Nephelometer (CIN) & Extinction at $100 \mathrm{~Hz}$, averaged to $10 \mathrm{~Hz}$ \\
\hline \multirow[t]{7}{*}{ RADIATION } & \multirow[t]{3}{*}{$\begin{array}{l}\text { Broadband } \\
\text { Irradiances }\end{array}$} & $\begin{array}{c}\uparrow \downarrow \text { Shortwave Kipp \& Zonen (a modified CM22; } \\
\text { BBSR) }\end{array}$ & $\begin{array}{c}0.2 \mathrm{~Hz} \text { for } 95 \% \text { response, logged at } 100 \mathrm{~Hz} \text { and stored at } 10 \\
\mathrm{~Hz} \text {; no dome/sink temperatures }\end{array}$ \\
\hline & & $\uparrow \downarrow$ Longwave Kipp \& Zonen (a modified CG4; BBIR) & Same as for shortwave \\
\hline & & $\uparrow \quad$ Sunshine Pyranometer (SPN1) & $\begin{array}{c}\text { Direct-diffuse partitioning; } 3-5 \mathrm{~Hz} \text { for } 95 \% \text { response, logged } \\
\text { at } 100 \mathrm{~Hz} \text { and stored at } 10 \mathrm{~Hz}\end{array}$ \\
\hline & \multirow{2}{*}{$\begin{array}{c}\text { Spectral } \\
\text { Irradiances }\end{array}$} & $\uparrow \downarrow$ Multifilter Radiometer (MFR) & 5-channels $415-867 \mathrm{~nm}$ with $1625 \mathrm{~nm}$ at $10 \mathrm{~Hz}$ \\
\hline & & $\uparrow \downarrow$ HydroRad-3 Hyperspectral Radiometer & $350-850 \mathrm{~nm}, 0.3-2.5 \mathrm{~nm}$ resolution every $1-6 \mathrm{sec}$ \\
\hline & \multirow{2}{*}{$\begin{array}{c}\text { Spectral } \\
\text { Radiances }\end{array}$} & $\uparrow$ or $\downarrow$ HydroRad-3 Hyperspectral Radiometer & $3^{\circ} \mathrm{FOV}, 350-850 \mathrm{~nm}, 0.3-2.5 \mathrm{~nm}$ res. every $1-6 \mathrm{sec}$ \\
\hline & & $\uparrow \downarrow$ Infrared Thermometer (IRT) & $10 \mathrm{~Hz}$ \\
\hline \multirow[t]{5}{*}{ AEROSOL } & $\begin{array}{c}\text { Cloud } \\
\text { Condensation } \\
\text { Nuclei (CCN) } \\
\end{array}$ & Dual-Column CCN Spectrometer & $\begin{array}{l}\text { Constant } 0.2 \% \text { supersaturation (SS) at } 1 \mathrm{~Hz} \\
\text { Full SS scan in } \sim 25 \min [0.8 \%, 0.57,0.4,0.28,0.2]\end{array}$ \\
\hline & \multirow[t]{4}{*}{ Size Distribution } & Two Condensation Nuclei Particle Counters (CPCs) & $\mathrm{D}>10 \mathrm{~nm}(\mathrm{CPC} 1)$, and $\mathrm{D}>15 \mathrm{~nm}(\mathrm{CPC} 2)$ at $1 \mathrm{~Hz}$ \\
\hline & & Ultrafine CPC (UPC or UFCPC) & $\mathrm{D}>3 \mathrm{~nm}$ at $1 \mathrm{~Hz}$ \\
\hline & & Scanning Differential Mobility Analyzer (DMA) & D from $12-600 \mathrm{~nm}$ every $\sim 60$ secs \\
\hline & & Passive Cavity Aerosol Spectrometer Probe (PCASP) & approximately $100-2,200 \mathrm{~nm}$ at $1 \mathrm{~Hz}$ \\
\hline \multirow{5}{*}{$\begin{array}{l}\text { ATMOSPHERIC } \\
\text { STATE }\end{array}$} & Temperature & Rosemount and Vaisala (backup) & $100 \mathrm{~Hz}$; Measurement uncertainty inside of cloud \\
\hline & \multirow[t]{2}{*}{ Water Vapor } & 2 Chilled Mirror Hygrometers (EdgeTech, CR2) & $\sim 1 \mathrm{~Hz}$ for $\mathrm{T}>-40^{\circ} \mathrm{C}$ \\
\hline & & Diode Laser Hygrometer (DLH) & $100 \mathrm{~Hz}$, No equilibration needed after leaving cloud \\
\hline & $\begin{array}{c}\text { Horizontal winds } \\
\text { and Updraft } \\
\text { Velocity }\end{array}$ & Determined from multiple aircraft sensors & $10 \mathrm{~Hz}$ \\
\hline & Conditions & Handheld photos and DAQ flight images/video & DAQ images every 1-2 sec; forward and side view \\
\hline
\end{tabular}


Table 2. Instrument PIs and e-mail addresses. Users of the data are strongly urged to contact instrument PIs about use of the data.

\begin{tabular}{|c|c|c|}
\hline Instrument & Instrument PI & E-mail \\
\hline $\begin{array}{c}\text { Gerber Probe, SEA LWC Probe, FSSP, CAPS } \\
\text { (CAS \& 1D CIP), CPCs, PCASP, temperature } \\
\text { (Rosemount) and water vapor (EdgeTech and } \\
\text { CR2), winds ( } U, V \text {, and } W) \text {, Aircraft flight } \\
\text { parameters }\end{array}$ & Haf Jonsson & hjonsson@nps.edu \\
\hline 2D CIP & $\begin{array}{l}\text { Greg McFarquhar and } \\
\text { Bobby Jackson }\end{array}$ & $\frac{\text { mcfarq@atmos.uiuc.edu, }}{\text { rjackso2@illinois.edu }}$ \\
\hline $2 \mathrm{D}-\mathrm{S}$ & $\begin{array}{l}\text { Paul Lawson and } \\
\text { Qixu Mo }\end{array}$ & $\frac{\text { plawson@specinc.com }}{\text { mo@specinc.com }}$ \\
\hline $\mathrm{CIN}$ & Hermann Gerber & hgerber6@comcast.net \\
\hline $\begin{array}{c}\text { Radiometers } \\
\text { (BBSR, BBIR, SPN1, IRT, MFR, Hydrorad) }\end{array}$ & $\begin{array}{l}\text { Anthony Bucholtz and } \\
\text { Chuck Long }\end{array}$ & $\frac{\text { bucholtz@nrlmry.navy.mil, }}{\text { chuck.long@pnl.gov }}$ \\
\hline $\mathrm{CCN}$ & Roy Woods & rkwoods@nps.edu \\
\hline DMA & Don Collins & dcollins@tamu.edu \\
\hline DLH & Glenn Diskin & Glenn.S.Diskin@nasa.gov \\
\hline
\end{tabular}

\subsection{Instrument and Data Status per Flight}

General data comments:

- Overall, the instrument complement worked well, especially for such a long, challenging campaign. On the occasion that an instrument issue arose, the measurement of the parameter usually had coverage via instrument redundancy.

- An exception occurred on 24 April, when the cabin file was not available (which contains navigation data and basic atmospheric state measurements) so all data (including those stored by other computers), if used, should be regarded carefully since they are difficult to post-process or interpret without the navigation data.

- In June, the extreme heat in the cabin caused some overheating issues with some instruments and/or their computers turned off for a short period during flight before operation was resumed.

Users of the data are strongly urged to contact instrument PIs about use of the data. Further, it is highly recommended that studies using the data be done in collaboration with the instrument PIs, since they are in the best position to provide insights and or caveats associated with the data that should be considered.

Table 2 provides summaries of the instrument status for each flight, which are also reflected in the Flight Details (http://campaign.arm.gov/racoro/flights) under “Aircraft Instrumentation Status.” The table is accompanied by brief summaries of the instrument operations during the campaign. You are $\underline{\text { URGED }}$ to consult the data readme files that accompany the data in the Data Archive. 
Table 3. Summaries of the instrument status per mission.

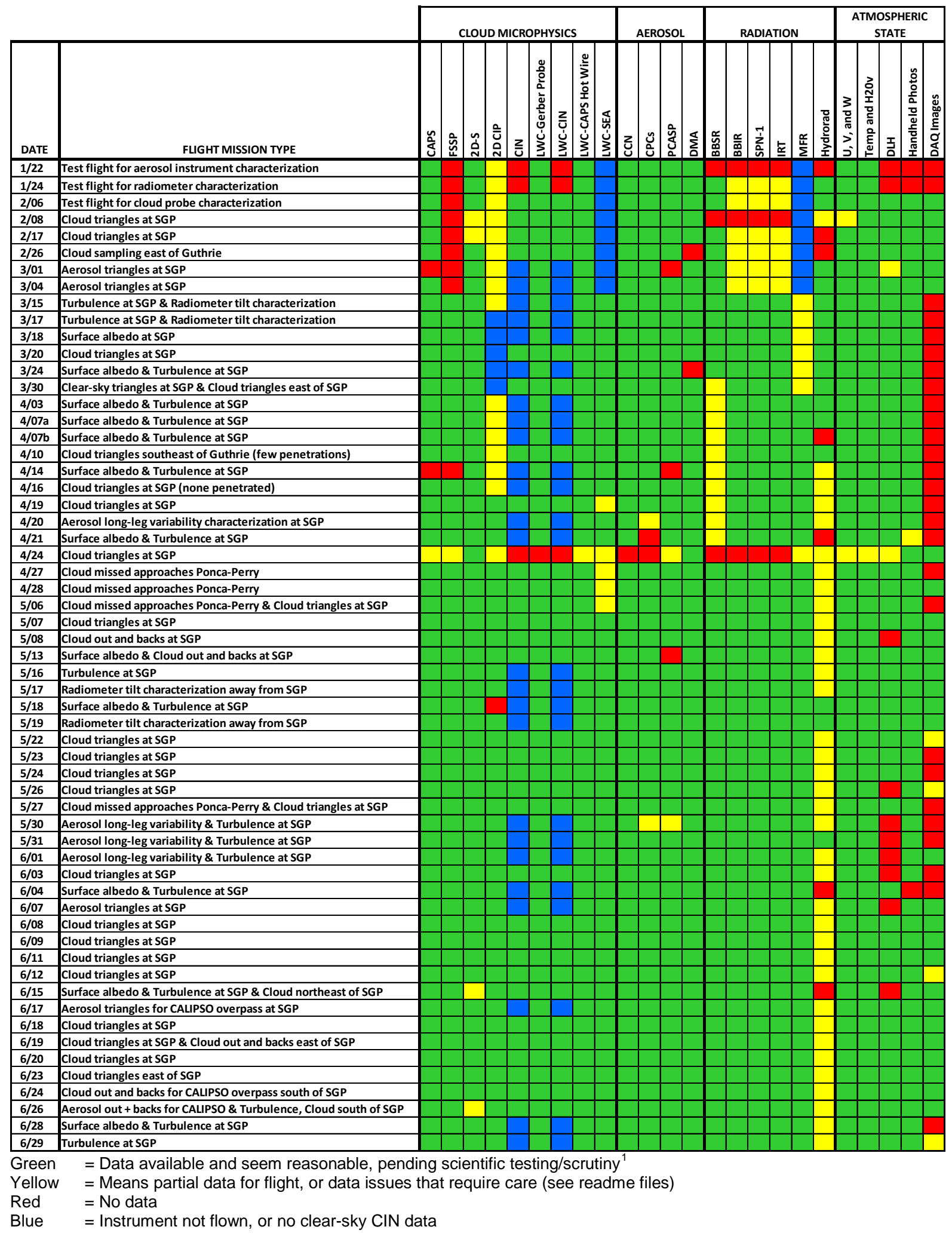

${ }^{1}$ Assessing the data quality requires additional checks and scientific use of the data. "Green" means that the data are available and appear good based on bounds checking and cursory comparisons with similar datastreams. 


\subsubsection{Cloud Microphysics Measurements}

Data consistency and quality control checks among the different cloud probes are being conducted by Greg McFarquhar, mcfarq@atmos.uiuc.edu, for the "Cloud Best Estimate Product.” As of March 2012, based on existing findings, the CAS is the preferred instrument for LWC, drop size distribution, and effective radius calculations. See the "Cloud Best Estimate Product” for further details.

\section{CAPS (Cloud, Aerosol Precipitation Spectrometer)}

The CAPS (which contains the CAS [Cloud and Aerosol Spectrometer] and 1D CIP [1D Cloud Imagine Probe]) was robust throughout the campaign. Some negative counts in the bin-resolved concentrations occur as an artifact of processing and should be ignored (i.e., they should have been zeros). Data for 20 June exist, but are absent from the summary files (Cabin or Merged files).

\section{FSSP (Forward Scattering Spectrometer Probe)}

Initially (through 4 March), particle sizing seemed fine, but the particle concentrations were too low. From 15 March, this issue was resolved operating the FSSP in Range 1, which reduces the maximum drop size bin from 45 to $30 \mu \mathrm{m}$ and increases the bin resolutions slightly. FSSP data are available from 15 March onwards. There is a potential tendency for measurement drift. The FSSP concentrations and LWC for most days in the original data release should be multiplied by 1.71 (to be corrected in subsequent data release).

\section{D CIP (2D Cloud Imaging Probe)}

Yellow until the 19 April flight indicates a period when a stuck bit was persistent. A fix for the stuck bit was implemented in the software, but there are more uncertainties in deriving size distributions for the earlier flights. (See the 2D CIP readme file for more details and for discussion of comparisons with the 1D CIP, which are currently under further investigation by Greg McFarquhar, mcfarq@atmos.uiuc.edu.)

\section{D-S (2D Stereo Probe)}

Functioned well. Yellow for cases when the vertical arm was not functioning (but data good from the horizontal arm), or in June when cabin overheating required for it to be shut down for a brief period during flight.

\section{CIN (Cloud Integrating Nephelometer)}

The CIN measures cloud optical extinction coefficient and asymmetry parameter (hence, no data for missions that do not have cloud penetrations). Clear-air offsets found in the DOE CIN instrument suggest that the smallest extinction coefficient values will be somewhat larger than is possible, being about $4 \mathrm{~km}^{-1}$ to $220 \mathrm{~km}^{-1}$ (these values correspond with visual ranges of $\sim 1 \mathrm{~km}$ to $\sim 0.018 \mathrm{~km}$ ). See CIN readme files for more details.

\section{LWC (Liquid-Water Content; Gerber, CIN, SEA, CAPS Hot Wire)}

Instrument redundancy provided multiple measures of liquid-water content (LWC; see note above about CAS LWC use). 
Gerber Probe: Was robust throughout the campaign, and also provides estimates of the cloud effective radius (Reff; see note above about CAS Reff use). (Note that the Gerber Probe has a drop-size sensitivity roll off that starts $\sim 30 \mu \mathrm{m}$; Wendisch et al [2002].) Negative Gerber LWC results from electronic noise in clear skies and should be ignored.

SEA WCM-2000 sensor (LWC only): Was installed later in the campaign (15 March) and should provide a measurement of comparable quality, except in initial flights where a popped circuit breaker could cause negative LWC for the remainder of the flight (yellow in Table 2; fixed before the 7 May flight).

CIN and CAPS Hot-Wire Probe: LWC was also determined from the CIN (see note above about instrument sensitivity) and from the hot-wire probe in the CAPS (available for completeness, but it is noisier and less robust that other LWC measurements and should be used carefully, if at all).

\subsubsection{Aerosol Measurements}

\section{CCN (Cloud Condensation Nuclei)}

Measurements made using the Droplet Measurement Technologies Dual-Column CCN Spectrometer (CCN-200). One column is held at $0.2 \%$ supersaturation and reports at $1 \mathrm{~Hz}$. The second column takes about 25 minutes to scan through a range of supersaturations, starting at $0.8 \%$ down to $0.2 \%$ [0.8, 0.57 , $0.4,0.28,0.2]$ before jumping back to $0.8 \%$. The archived data have been corrected for variations in the static pressures of the aircraft. The “Adjusted Cloud Condensation Nuclei Concentrations” data set (provided by Betsy Andrews and John Ogren [betsy.andrews@noaa.gov, john.a.ogren@noaa.gov]) provides further corrections for the variations possible in the set-point supersaturations.

\section{CPCs (Condensation Particle Counters)}

Three CPCs were flown for fast-response CN counts. The CN-counter detection thresholds were: Ultrafine (> $3 \mathrm{~nm}$ ); CPC1 (>10 nm); and CPC2 (> 15 nm; "approximately," because the efficiency curve had a significant slope to it at the threshold, but the CPC\#1 was very steep, i.e., when it kicked on it quickly went to $100 \%$ efficiency).

Red: 21 April - data not valid but values present in some files. Yellow: 20 April, CPC2 data invalid (but other CPC data okay); 30 May, CPCs not functioning for last hour of flight.

\section{PCASP (Passive Cavity Aerosol Spectrometer Probe)}

Functioned well; missing data was from computer-initiation issues.

\section{DMA (Differential Mobility Analyzer)}

The DMA functioned well. The downtimes were due to computer-initiation issues.

\subsubsection{Radiation Measurements}

\section{BBSR (Broadband shortwave irradiance)}


Zenith instrument experienced occasional drop-outs on most flights due to interference from one of the aircraft radios (flagged as -9999.0).

Yellow 30 March-21 April: Zenith (upward-looking) values max out $\sim 1,000 \mathrm{Wm}^{-2}$ (mainly in turns) but most level-flight data are fine.

\section{BBIR (Broadband longwave irradiance)}

Zenith instrument experienced occasional drop outs on most flights due to interference from one of the aircraft radios (flagged as -9999.0).

Yellow: Nadir (downward-looking) instrument's case temperature had an offset, which was fixed before the 15 March flight (nadir BBIR case temperature used for all flights for consistency).

\section{SPN-1 (Broadband shortwave total and diffuse irradiance)}

Yellow: Initially experienced high-frequency noise (RMS), which was fixed before the 15 March flight.

\section{IRT (Infrared Thermometer)}

Yellow: Initially the upward-looking (zenith-viewing) IRT would bottom out in very cold and/or clear cases $\left(<\sim-50^{\circ} \mathrm{C}\right)$. It was replaced before the 15 March flight with a model that goes to $-100^{\circ} \mathrm{C}$. (Nadirviewing instrument performed fine.)

\section{MFR (Multifilter Radiometer)}

The MFR heads were installed in mid-March. Facilities do not exist to calibrate the $1.6 \mu \mathrm{m}$ channel, so the upward and downward channels were calibrated side-by-side (i.e., relative to one another) for determination of the $1.6 \mu \mathrm{m}$ albedo. Initial flights showed noise (RMS) in channels 2-6 that can be averaged out. The noise was eliminated when larger capacitors were installed (before the 24 April flight).

Yellow 15-30 March: Initial logger problems yielded $1 \mathrm{hr}$ of data per flight, which was fixed before the 3 April flight.

\section{Hydrorad}

Sometimes referred to in the notes as the Aerorad, but both names refer to the same instrument, and Hydrorad is its proper name (from Hobi labs). We had no prior experience with this instrument and were learning and modifying its operation during the campaign. The data acquisition system was upgraded a couple of times during RACORO, and the exposure settings were modified a number of times to optimize the sampling frequency and negotiate the dynamic range of the instrument between overexposure in the middle channels vs. underexposure/noise at the longest wavelengths. Although an observation (dwell time) takes $~ 50-100 \mathrm{~ms}$, Table 1 indicates the reporting is every 1-6 sec because of the time needed to record the three high-resolution spectra. Changes are all documented in the Hydrorad readme file, including the direction of the radiance probe (which could easily be changed preflight between zenith or nadir). Yellow usually means that the data are present, but that portions of some spectra (the middle channels) are saturated (but the non-saturated channels are likely good). 


\subsubsection{Atmospheric State Measurements}

\section{$\mathrm{U}, \mathrm{V}$, and $\mathrm{W}$}

Uses improved wind retrieval algorithm that were post-processed circa July 2010. Use vertical velocities only during level flight.

\section{Temperature and H2Ov (water vapor)}

Check the CIRPAS Cabin readme files. Usually the dew point is obtained from the EdgeTech; however, if it is too cold/dry, the CR2 is used instead (has a wider range, but a slower response). Chilled mirror water vapor measurements are not valid in cloud; for in-cloud measurements, use the DLH. Temperature is usually obtained by the Rosemount probe, with the Vaisala serving as a backup. There was not a reverse flow on the thermometer so there are likely temperature biases that are a function of LWC. The accuracy of this instrument has been reported to be $0.3 \mathrm{C}$ in clear sky, ramping to $-1^{\circ} \mathrm{C}$ for LWC of $2 \mathrm{~g} \mathrm{~m}^{3}$ (see Lawson and Cooper 1990; Fig. 8b).

\section{DLH (Diode Laser Hygrometer)}

The DLH measures water vapor mixing ratio using an external-path measurement of water vapor concentration using Wavelength-Modulated Tunable Diode Laser Absorption Spectroscopy, and can measure at rates up to $100 \mathrm{~Hz}$. It functioned well during the campaign; any downtimes were associated with computer issues (initiation or heat). (Note: DLH data exists for 8 February, but is not in the Merged file.)

\section{Handheld Photos}

Provide a brief overview of the cloud field or land surface conditions sampled.

\section{DAQ Images/video}

The DAQ (short for Data Acquisition system) images (that can be used to produce videos) were not considered a primary instrument and therefore received attention last. There were data issues after some instrument modifications and were also some download problems. Yellow means that data are available for some part of the flight. (Although the DAQ videos are not always available, handheld photos show the appearance of the cloud field or land surface.)

\subsection{RACORO Data Distribution}

Users of the data are strongly urged to contact instrument PIs about use of the data. Further, it is highly recommended that studies using the data be done in collaboration with the instrument PIs, since they are in the best position to provide insights and or caveats associated with the data that should be considered. 


\subsection{IOP Archive Data Files}

To assist users in finding the desired data, Table 4 lists the data sets available on the RACORO IOP Archive and provides a summary description of the content including their observation frequency (usually 1 to $10 \mathrm{~Hz}$ ). They are categorized approximately by their primary type/function:

- Summary/Merged Data

- Cloud Microphysics

- Water Vapor

- Aerosol

- Radiation

- Atmospheric Conditions

- Modeling

Handheld photos (in addition to the DAQ images and GOES visible imagery) captured the atmospheric conditions, which are available from different locations:

- Handheld pictures from the flights are downloadable from the web from the Flight Details (the same photos are available from the Campaign Journal).

- Some additional handheld flight photos are available from the data archive at this location arranged by date.

- Also, some pictures of the instruments and flight operations are available from the ARM images gallery.

\subsection{Merged and Enhanced Data Sets}

Beyond the calibrated data in the archive, there are several efforts (completed or ongoing) to provide merged data sets and enhance the data sets:

\section{Summary/Merged Data sets:}

- Merged Data files: Provides a comprehensive set of measurements from multiple instruments (and PIs) in a single file. (Note: LWC units are CC/m3, not microgram $/ \mathrm{m} 3$ as in header.)

- CIRPAS Cabin: Contains CIRPAS cabin data that include the original aircraft flight parameters and many cross-disciplinary measurements. (“CIRPAS Basic Parameters” are the same files.)

\section{Enhanced Data sets:}

- Radiation Measurements: The downwelling (i.e., zenith-viewing or upwards-looking) shortwave broadband measurements have the effects of non-level aircraft attitude removed as per Long et al. (2010), which works well up to $\pm 10^{\circ}$ of tilt. The same method is applied to MFR spectral data, but assumes that the broadband ratio represents spectral channel response to tilt, which appears to remove about two-thirds of the tilt influence but is not as good as the broadband correction (under further investigation). These radiation data are identified in the archive with the "tilt corrected" prefix. 
- Merged CAS and 2D-S Particle Size Distributions: Provides particle size distribution diameters from 0.6 to $1280 \mu \mathrm{m}$ by merging 2D-S and CAS data.

- Cloud Measurements: Ongoing work is conducting consistency and mass-balance checks on the multiple cloud microphysics data sets (LWC and drop-size distributions) in order to synthesize them into best-estimate products that will be available to the community. (For further information, contact Greg McFarquhar; mcfarq@atmos.uiuc.edu.)

- Aerosol Measurements: The CCN supersaturation values are corrected for variations caused by flight conditions in the "Adjusted Cloud Condensation Nuclei Concentrations" data set. Optical properties have been computed from the aerosol size distributions in the "Aerosol Optical Properties" data set. 
Table 4. Contents of data sets listed on the RACORO IOP Archive. Users of the data are strongly urged to contact instrument PIs about use of the data.

\begin{tabular}{|c|c|}
\hline Campaign Participant & $\begin{array}{l}\text { IOP Archive Data set Name } \\
\text { Data frequency and Primary Type/description }\end{array}$ \\
\hline \multicolumn{2}{|r|}{ SUMMARYIMERGED DATA } \\
\hline $\begin{array}{l}\text { Comstock, Jennifer and } \\
\text { Lo, Chaomei } \\
\text { jennifer.comstock@pnl.gov, } \\
\text { chaomei.lo@pnl.gov }\end{array}$ & $\begin{array}{l}\text { Merged Data files (based on multiple instruments) } \\
1 \mathrm{~Hz} \text {; Aircraft flight parameters, pressure, winds (U, V, W), temperature, } \\
\text { potential temperature, equivalent potential temperature, water vapor (dew } \\
\text { point, water vapor mixing ratio, relative humidity, specific humidity), LWC, } \\
\text { cloud Reff, cloud drop number and volume concentrations, aerosol number } \\
\text { and concentrations, broadband shortwave irradiance (tilt-corrected), } \\
\text { broadband longwave irradiance, infrared temperature, cloud extinction } \\
\text { coefficient and asymmetry parameter. Quicklook plots are available for each } \\
\text { day. }\end{array}$ \\
\hline $\begin{array}{l}\text { Jonsson, Haflidi } \\
\text { hjonsson@nps.edu }\end{array}$ & $\begin{array}{l}\text { CIRPAS Cabin (or CIRPAS Basic Parameters) } \\
\text { Aircraft flight parameters, Temperature, Dew point temperature, Pressure, } \\
\text { IRT, LWC, Reff and: } \\
10 \mathrm{~Hz} \text { : Integral total particle concentration and particle volume from CAPS } \\
1 \mathrm{~Hz}: \text { Total particle concentration (CPCs, PCASP, CAPS, FSSP) and particle } \\
\text { volume (PCASP, CAPS, FSSP) }\end{array}$ \\
\hline \multicolumn{2}{|r|}{ CLOUD MICROPHYSICS } \\
\hline $\begin{array}{l}\text { Jonsson, Haflidi } \\
\text { hjonsson@nps.edu }\end{array}$ & $\begin{array}{l}\text { Cloud and Aerosol Spectrometer (CAS) } \\
10 \mathrm{~Hz} \text {; Particle size distribution diameters from } 0.5 \text { to } \sim 50 \mu \mathrm{m}\end{array}$ \\
\hline $\begin{array}{l}\text { Jonsson, Haflidi } \\
\text { hjonsson@nps.edu }\end{array}$ & $\begin{array}{l}\text { Cloud, Aerosol and Precipitation Spectrometer (CAPS) } \\
1 \mathrm{~Hz} \text {; CAPS (CAS \& 1D CIP) particle size distribution diameters } 0.5-1550 \mu \mathrm{m}\end{array}$ \\
\hline $\begin{array}{l}\text { Lawson, Paul } \\
\text { plawson@specinc.com }\end{array}$ & $\begin{array}{l}\text { Merged CAS and 2D-S Particle Size Distributions } \\
1 \mathrm{~Hz} \text {; Particle size distribution diameters from } 0.6 \text { to } 1280 \mu \mathrm{m} \text { by merging 2D- } \\
\text { S and CAS data }\end{array}$ \\
\hline $\begin{array}{l}\text { Jonsson, Haflidi } \\
\text { hjonsson@nps.edu }\end{array}$ & $\begin{array}{l}\text { Forward Scattering Spectrometer Probe (FSSP) } \\
\quad 1 \mathrm{~Hz} \text {; Particle size distribution diameters from } 2 \text { to } \sim 30 \mu \mathrm{m}\end{array}$ \\
\hline $\begin{array}{l}\text { McFarquhar, Greg } \\
\text { mcfarq@atmos.uiuc.edu }\end{array}$ & $\begin{array}{l}\text { Two-Dimensional Cloud Imaging Probe (2D CIP) } \\
1 \mathrm{~Hz} \text {; Particle size distribution diameters from } 50 \text { to } 1600 \mu \mathrm{m}\end{array}$ \\
\hline $\begin{array}{l}\text { Gerber, Hermann } \\
\text { hgerber6@comcast.net }\end{array}$ & $\begin{array}{l}\text { Cloud Integrating Nephelometer (CIN) } \\
10 \mathrm{~Hz} \text { (aves of } 100 \mathrm{~Hz} \text { ); Cloud extinction and asymmetry parameter }\end{array}$ \\
\hline $\begin{array}{l}\text { McFarquhar, Greg, Jackson, } \\
\text { Robert, and } \\
\text { Yang, Hee-Jung } \\
\text { mcfarq@atmos.uiuc.edu, } \\
\text { rjackso2@atmos.uiuc.edu, } \\
\text { hyang31@atmos.uiuc.edu }\end{array}$ & $\begin{array}{l}\text { Best Estimate Cloud Microphysics Parameters } \dagger \\
\text { Based on all aircraft cloud microphysics observations }\end{array}$ \\
\hline \multicolumn{2}{|r|}{ WATER VAPOR } \\
\hline $\begin{array}{l}\text { Diskin, Glenn } \\
\text { Glenn.S.Diskin@nasa.gov }\end{array}$ & $\begin{array}{l}\text { Diode Laser Hygrometer (DLH) } \\
1 \mathrm{~Hz}, 10 \mathrm{~Hz} \text { (and } 100 \mathrm{~Hz} \text { upon request); Water vapor mixing ratio }\end{array}$ \\
\hline \multicolumn{2}{|r|}{ AEROSOL } \\
\hline $\begin{array}{l}\text { Woods, Roy } \\
\text { rkwoods@nps.edu }\end{array}$ & $\begin{array}{l}\text { Dual-Column Cloud Condensation Nuclei Counter } \\
\text { CCN at } 1 \mathrm{~Hz} \text { (for supersaturation } 0.2 \% \text { ), } \sim 25 \text { min for full scan (0.8 to } 0.2 \%) \text {. }\end{array}$ \\
\hline
\end{tabular}

†Tentative name; data to be released in the future. 


\begin{tabular}{|c|c|}
\hline \multicolumn{2}{|r|}{ Table 4 (contd) } \\
\hline $\begin{array}{l}\text { Andrews, Elisabeth and } \\
\text { Ogren, John } \\
\text { betsy.andrews@noaa.gov, } \\
\text { john.a.ogren@noaa.gov }\end{array}$ & $\begin{array}{l}\text { Adjusted Cloud Condensation Nuclei Concentrations } \\
\text { CCN concentrations corrected for actual operating conditions } \\
\text { (e.g., the effect of different pressures on the set-point } \\
\text { supersaturations). }\end{array}$ \\
\hline $\begin{array}{l}\text { Jonsson, Haflidi } \\
\text { hjonsson@nps.edu }\end{array}$ & $\begin{array}{l}\text { Passive Cavity Aerosol Spectrometer (PCASP) } \\
1 \mathrm{~Hz} \text {; Particle size distribution diameters from } \sim 0.1 \text { to } 2.2 \mu \mathrm{m}\end{array}$ \\
\hline $\begin{array}{l}\text { Collins, Don } \\
\text { dcollins@tamu.edu }\end{array}$ & $\begin{array}{l}\text { Differential Mobility Analyzer (DMA) } \\
\text { Every } \sim 60 \mathrm{sec} \text {; Particle size distribution diameters from } 0.012 \text { to } \\
0.6 \mu \mathrm{m}\end{array}$ \\
\hline $\begin{array}{l}\text { Andrews, Elisabeth and } \\
\text { Ogren, John } \\
\text { betsy.andrews@noaa.gov, } \\
\text { john.a.ogren@noaa.gov }\end{array}$ & $\begin{array}{l}\text { Aerosol Optical Properties } \\
\text { Aerosol optical properties are computed from the measured } \\
\text { aerosol size distributions (e.g., for comparison with the HSRL } \\
\text { aerosol extinction profiles). Also includes four indicators of } \\
\text { potential cloud contamination. }\end{array}$ \\
\hline \multicolumn{2}{|r|}{ RADIATION } \\
\hline $\begin{array}{l}\text { Bucholtz, Anthony } \\
\text { bucholtz@nrlmry.navy.mil }\end{array}$ & $\begin{array}{l}\text { Radiometers } \\
10 \mathrm{~Hz} \text {; IRT, BBIR, BBSR, SPN-1 (shortwave measurements not } \\
\text { tilt-corrected) }\end{array}$ \\
\hline $\begin{array}{l}\text { Long, Chuck } \\
\text { chuck.long@pnl.gov }\end{array}$ & $\begin{array}{l}\text { Tilt Corrected Radiation Files } \\
10 \mathrm{~Hz} \text {; Aircraft flight parameters, IRT, BBIR, BBSR, SPN1. } \\
\text { Shortwave zenith measurements have tilt-corrections (BBSR, } \\
\text { SPN1). }\end{array}$ \\
\hline $\begin{array}{l}\text { Long, Chuck } \\
\text { chuck.long@pnl.gov }\end{array}$ & $\begin{array}{l}\text { Tilt Corrected Radiation and MFR Calibrated Files } \\
10 \mathrm{~Hz} \text {; As above but also with the MFR irradiances (zenith } \\
\text { measurements tilt-corrected) and narrowband albedos from the } \\
\text { MFR channels }\end{array}$ \\
\hline $\begin{array}{l}\text { Bucholtz, Anthony } \\
\text { bucholtz@nrlmry.navy.mil }\end{array}$ & $\begin{array}{l}\text { Hydrorad-3 Spectroradiometert } \\
\text { Every 1-6 sec; 350-850 nm, resolution set between } 0.3 \text { and } 2.5 \\
\text { nm. Radiance measurement usually zenith-viewing, but nadir- } \\
\text { viewing at start }\end{array}$ \\
\hline \multicolumn{2}{|r|}{ ATMOPSHERIC CONDITIONS } \\
\hline $\begin{array}{l}\text { Comstock, Jennifer } \\
\text { jennifer.comstock@pnnl.gov }\end{array}$ & $\begin{array}{l}\text { DAQ Images/Movies } \dagger \\
0.5-1 \mathrm{~Hz} ; \text { Forward view and side view }\end{array}$ \\
\hline $\begin{array}{l}\text { Cooper, Owen } \\
\text { owen.r.cooper@noaa.gov }\end{array}$ & $\begin{array}{l}\text { GOES Visible Imagery } \\
\text { Every } 30 \text { mins; the images cover central Oklahoma and } \\
\text { Oklahoma/Kansas }\end{array}$ \\
\hline \multicolumn{2}{|r|}{ MODELING } \\
\hline $\begin{array}{l}\text { Xie, Shaocheng } \\
\text { xie2@Ilnl.gov }\end{array}$ & $\begin{array}{l}\text { Cloud Modeling Best Estimate- Cloud and Radiation } \\
\text { At the SGP; hourly means of precipitable water vapor, liquid-water } \\
\text { path, cloud fraction, surface radiative fluxes, and satellite-retrieved } \\
\text { radiative fluxes and clouds }\end{array}$ \\
\hline $\begin{array}{l}\text { Xie, Shaocheng } \\
\text { xie2@\|lnl.gov }\end{array}$ & $\begin{array}{l}\text { Constrained Variational Objective Analysis Data } \\
\text { SGP domain; contains hourly large-scale forcing data (for driving } \\
\text { Single-Column and Cloud-Resolving Models) and evaluations } \\
\text { fields (for evaluating the simulations) }\end{array}$ \\
\hline
\end{tabular}

† Tentative name; data to be released in the future. 


\subsection{References}

Cairns, B, F Waquet, K Knobelspiesse, J Chowdhary, and JL Deuzé. 2009. "Polarimetric remote sensing of aerosols over land surfaces.” Satellite Aerosol Remote Sensing Over Land, AA Kokhanovsky and G de Leeuw, Eds., Springer, Chichester, UK, 295-325.

Hair, JW, CA Hostetler, AL Cook, DB Harper, RA Ferrare, TL Mack, W Welch, LR Izquierdo, FE Hovis. 2008. "Airborne High Spectral Resolution Lidar for Profiling Aerosol Optical Properties.” Applied Optics 47: doi:10.1364/AO.47.006734.

Hegg, DA, DS Covert, H Jonsson, and PA Covert. 2005. "Determination of the transmission efficiency of an aircraft aerosol inlet.” Aerosol Science and Technology 39: 966-971, doi:10.1080/02786820500377814.

Lawson, RP, and WA Cooper. 1990. "Performance of some airborne thermometers in clouds.” Journal of Atmospheric and Oceanic Technology 7: 480-494.

Long, CN, A Bucholtz, H Jonsson, B Schmid, A Vogelmann, and J Wood. 2010. “A method of correcting for tilt from horizontal in downwelling shortwave irradiance measurements on moving platforms.” “The Open Atmospheric Science Journal 4: doi:10.2174/1874282301004010078.

Rogers, RR, JW Hair, CA Hostetler, RA Ferrare, MD Obland, AL Cook, DB Harper, SP Burton, Y Shinozuka, CS McNaughton, AD Clarke, J Redemann, PB Russell, JM Livingston, and LI Kleinman. 2009. "NASA LaRC airborne high spectral resolution lidar aerosol measurements during MILAGRO: observations and validation.” Atmospheric Chemistry and Physics 9: 4811-4826.

Vogelmann, AM, GM McFarquhar, JA Ogren, DD Turner, JM Comstock, G Feingold, CN Long, HH Jonsson, A Bucholtz, DR Collins, GS Diskin, H Gerber, RP Lawson, RK Woods, E Andrews, H-J Yang, JC Chiu, D Hartsock, JM Hubbe, C Lo, A Marshak, JW Monroe, SA McFarlane, B Schmid, JM

Tomlinson, and T Toto. 2012. "RACORO Extended-Term, Aircraft Observations of Boundary-Layer Clouds.” Bulletin of the American Meteorological Society. In press. Early online release at http://journals.ametsoc.org/doi/pdf/10.1175/BAMS-D-11-00189.1

Wendisch, M, TJ Garrett, and JW Strapp. 2002. "Wind tunnel tests of the airborne PVM-100A response to large droplets.” Journal of Atmospheric and Oceanic Technology 19: 1577-1584. 


\section{Appendix A Mission Flight Patterns}




\section{Mission Flight Patterns}

The patterns described here are:

\section{CLOUDY-SKY PATTERNS}

f. Cloud Triangles Flight Plan

g. Cloud Missed Approaches Flight Plan

h. Cloud Out-and-Back Flight Plan

\section{OTHER PATTERNS}

i. Surface Albedo Flight Plans

j. Turbulence Flight Plan

k. Radiometer Tilt Characterization Flight Plan

l. Aerosol Triangles Flight Plan

m. Aerosol Long-Leg Variability Characterization Flight Plan

These names are used in the headers for the Campaign Journal and Flight Details to identify the mission type. Note that the patterns could be modified by the pilots if the conditions warranted it so, to know what was flown, be sure to consult the pilot notes within the Flight Details.

Terms/abbreviations used in the descriptions are as follows.

Above Ground Level (AGL) = Mean sea level (MSL) minus about $1000 \mathrm{ft}$ (ground altitudes w/in the SGP region are 990 to $1013 \mathrm{ft}$ );

ATC: Air Traffic Control

IFR: Instrument flight rules (i.e., cloudy)

RSC: RACORO Steering Committee

SGP: Southern Great Plains ARM site, also sometimes referred to as CF (Central Facility)

VFR: Visual Flight Rules

$\mathrm{Zb}=$ Cloud base; $\mathrm{Zt}=$ Cloud top

\section{CLOUDY-SKY PATTERNS}

\section{A. Cloud Triangles Flight Plan (See Figure A.1)}

(The triangles had legs $\sim 30-40 \mathrm{~km}$ long with a vertex over the SGP. The triangle was oriented so that the leg over the SGP was along the wind direction, but it almost always was along the east-west direction.)

0: Ferry to the SGP below cloud base at Zb-500 ft (150 m) 
1: Fly triangle below cloud at $\mathrm{Zb}-500 \mathrm{ft}$

2: Over SGP, perform spiral ascent from $500 \mathrm{ft}$ AGL to Zt+1500 ft (450 m)

3: Fly triangle above cloud at $\mathrm{Zt}+500 \mathrm{ft}$

4-6: Fly 3 triangles in cloud at 3 different levels (high, middle, low)

7: Over SGP, perform spiral ascent cloud from either:

- Minimum VFR height (500 ft AGL) IF broken cloud OR Zb > minimum vector altitude (see Note 1 below)

- Otherwise, start at lowest in-cloud level

8: Ferry back: fly back at $\mathrm{Zt}+500 \mathrm{ft}$ and at the half-way point, drop to middle-cloud level and finish ferry back.

Note 1: Minimum vector altitude is around $2500 \mathrm{ft}$ AGL (3500 MSL); however, air traffic control had been granted for $2300 \mathrm{ft}$ AGL.

Note 2: Pilot needs cloud base > $2500 \mathrm{ft}$ MSL (1500 AGL) to fly under it (VFR)

Note 3: On 27 May, the pattern was modified slightly to overfly Tomography IOP array by: (1) fixing the triangle orientation with the north-south leg over the SGP and tomography array and (2) extending the leg north of the CF by $5 \mathrm{~km}$.

Note 4: On 30 May, flights were moved from Guthrie to start from Ponca.

Note 5: After 12 June, the order of legs and cloud penetrations were modified for improved NASA KingAir coordination:

1. Climb out to above cloud at CF.

2. Fly above-cloud triangle.

3. Fly spiral profile from above cloud to $500 \mathrm{ft}$ AGL.

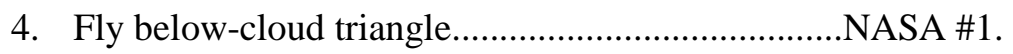

5. Fly bottom in-cloud triangle.......................................... \#ASA \#2.

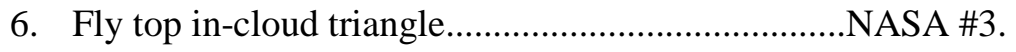

7. Fly additional in-cloud triangles as fuel allows at altitudes to sample deep clouds or maximize time in shallow clouds.

8. Climb to above cloud.

9. Fly spiral profile from above cloud to $500 \mathrm{ft}$ AGL,

10. Return to base below cloud. 


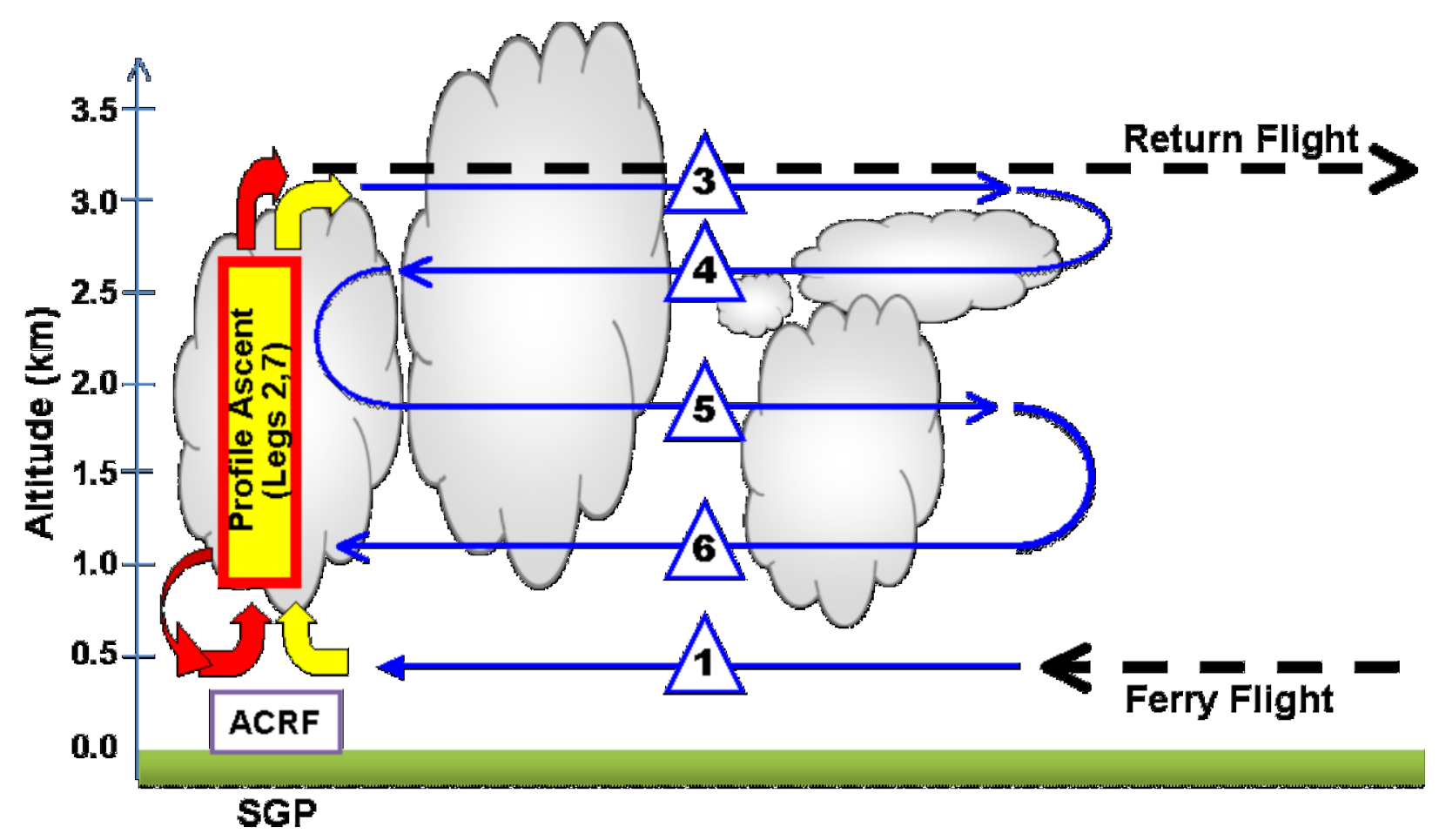

Figure A.1. Standard cloud triangles flight pattern.

\section{B. Cloud Missed Approaches Flight Plan}

This strategy was used when clouds were at or below the minimum vector altitude ( 2500 AGL or 3500 MSL) and were therefore too low for the needed radar coverage over the SGP; however, these clouds could be sampled by missed approaches between two airports. One pairing that was used was from Ponca to Perry, which provided a 22-mile stretch that bisected the western side of our standard cloud triangle in (A). The pilot requested approaches at different altitudes (in this example, going from Ponca towards Perry). When the Perry was reached, they turned and climbed to a high level and, when they reached Ponca, turned and reset at a new altitude. This enabled penetrations at multiple heights for these low clouds (subject to ATC approval for each height) and provided excellent in-cloud sampling.

\section{Cloud Out-and-Back Flight Plan}

This pattern was useful in two types of instances when we had a limited time window to obtain cloud sampling over the SGP:

When conditions were changing rapidly and the cloud was likely to dissipate quickly (and not allow the full sampling pattern "A").

When conditions changed during the execution of another flight pattern (e.g., Plan B) that enabled sampling of clouds over the SGP.

To obtain cloud data within a limited time window, we only sampled the along-wind leg over the SGP in plan “A” (i.e., as per the 1 May RSC teleconference, it was preferred to get a complete characterization at multiple levels of one leg vs. a limited-level sampling of the full triangle). Each 30-km leg took about 15 min to fly (depending on winds, or $\sim 30$ min for a complete out and back). This was a dynamic condition, 
and it was the pilot's discretion as to which of the following conditions/preferences applied for the best sampling of the cloud field present:

- Multiple within-cloud were needed if the cloud thickness $>250 \mathrm{~m}$ or $\sim 800 \mathrm{ft}$ (i.e., slice 'n dice);

- "Boundary conditions" (BC) were also needed at cloud base minus $500 \mathrm{ft}$ and at cloud top plus $500 \mathrm{ft}$. The cloud base minus $500 \mathrm{ft}$ is the most important BC;

- Particularly if the cloud field was changing quickly, each "out" and "back" should be flown at a different level;

- Perform spirals from $500 \mathrm{ft}$ AGL to cloud top plus $1500 \mathrm{ft}$ at the start and end of the plan if there was sufficient time (each about 10-15 mins). If the cloud field was threatening to dissipate, only perform the spiral at the end of the pattern.

\section{OTHER PATTERNS}

These patterns were flown when boundary-layer clouds were not present. The radiometer tilt characterization pattern (F) required clear skies, but the other patterns could be flown with clear skies or when upper-level clouds were present.

\section{Surface Albedo Flight Plans}

Two complementary patterns were used to characterize the surface albedo around the CF: a pinwheel pattern and a paper clip pattern.

1. Pinwheel Pattern: fly six level legs over the CF as low as possible ( $\sim 500 \mathrm{ft}$ AGL). The legs will have a "pinwheel" configuration centered on the CF, consisting of six $30^{\circ}$ wedges (spans $360^{\circ}$ ). Each leg is 20-km long, so there is $10 \mathrm{~km}$ on either side of the SGP. This provides the best albedo characterization for the CF instrumentation.

2. Paper clip pattern: Based on the RASAM proposal (McFarlane et al.), whose objective was to fly 5 level legs within a 20-km box centered on the CF (i.e., a 5-km separation between legs). The legs were oriented SW-NE so that no legs could follow along a road (which run N-S or E-W). This provides the best albedo characterization of the region.

\section{E. Turbulence Flight Plan}

Characterize the turbulence structure in the boundary layer downwind from the CF.

1. After take-off from Guthrie, the aircraft should climb to find the top of the boundary layer. Ideally, a preview of the NAM forecast (or other model) results and the Raman lidar data from the previous afternoon should suggest about where this level will be. Determine the approximate wind direction at $2400 \mathrm{ft}$ MSL (about $500 \mathrm{~m}$ AGL) on the way up. Determine the direction to head fly towards the site so that at $60 \mathrm{~km}$ away from the site the plane can align with the wind direction and fly to the CF.

3. Descend to $2400 \mathrm{ft}$ and fly a level $60 \mathrm{~km}$ leg to the CF aligned with the wind ( 20 min).

4. If the boundary-layer depth is more than $3000 \mathrm{ft}$, then the ascend $500 \mathrm{ft}$, otherwise ascend $300 \mathrm{ft}$. Orient the aircraft with the wind and fly a level leg to the outer edge of the domain (another $60 \mathrm{~km}$ ). 
5. Ascend again (same increment as before), reorient aircraft with the wind, and fly a level leg back to the CF.

6. Repeat steps 3 and 4 until the top of the boundary layer is reached.

7. Descend to the minimum flight altitude to repeat the pattern of level legs again.

\section{F. Radiometer Tilt Characterization Flight Plan}

Required conditions:

- Hemispherically clear-sky conditions (need to avoid clouds and/or smoke plumes).

- Span a significant range of solar zenith angles and include data close to local solar noon. To sample a range of solar zenith angles, fly starting either in the morning OR afternoon, but need to include local solar noon at one end (beginning box pattern, or ending box pattern).

- Conduct patterns at the maximum sustainable altitude (12,500 ft) across the morning or afternoon that the flight occurs (to avoid boundary-layer aerosols and plumes from localized burning as much as possible).

- The pattern does NOT require flight over the SGP.

Three patterns are flown (see Figure. A.2):

1. A box pattern oriented with respect to the solar azimuth angle at the time, and should be flown as level as possible. The aircraft should head directly into the sun direction for the first side of the box for about a $10 \mathrm{~km} \mathrm{leg}$, then turn $90^{\circ}$ (to the right or left) for the next side of the box (10 km), then turn $90^{\circ}$ in the same direction as previously to be headed directly away from the sun direction, then finish with a $90^{\circ}$ turn (again in the same direction as the previous two turns) so that the direction is opposite that of the second side of the box pattern.

2. Fly diagonally kitty-corner across the box from one corner to corner (gray dashed line in above drawing). For this leg, the heading should be maintained and the aircraft flown with various aircraft pitch angles while maintaining a constant and level-as-possible roll angle. The purpose of this leg is to isolate the pitch offsets and effects, holding heading and roll constant. Pitch angles of \pm 2 , 5 , and $7^{\circ}$ are needed, and each held for at least 10 seconds in order to allow the CM-22 to settle down (the CM-22 95\% response time is about 5-7 seconds). For example, pitch the nose down $2^{\circ}$ for $10-15$ seconds, then pitch the nose up $2^{\circ}$ for $10-15$ seconds, then pitch the nose down for $5^{\circ}$ for $10-15$ seconds, etc...repeat the whole thing. This leg can be as long as needed to complete all six pitch angles several times; the important element is to maintain a constant heading and roll angle.

3. (See Note 1 ) Holding a constant roll angle at $\pm 2,5$, and $7^{\circ}$ while the aircraft completes a complete $360^{\circ}$ turn for each angle, while maintaining as close to a zero pitch angle as possible. (If it is not possible to do zero pitch, then holding at a constant pitch angle is needed, whatever the required pitch angle is. The important part is that the pitch angle remains as constant as possible around the entire $360^{\circ}$ circle.) For example, holding the aircraft roll at $2^{\circ}$ for a complete $360^{\circ}$ circle, then holding the aircraft at $-2^{\circ}$ roll for a complete $360^{\circ}$ circle (presumably turning in the opposite direction than $a+2^{\circ}$ roll), then holding a $+5^{\circ}$ roll angle for a complete $360^{\circ}$ circle, etc...

4. Repeat patterns 1, 2, and 3 above three times. 
Note 1: Starting 17 May, pattern was 3 not used (and we recommend its omission from future radiometer characterizations) due to the negative impact of altitude loss that occurs during the turns and its impact on the radiation levels.

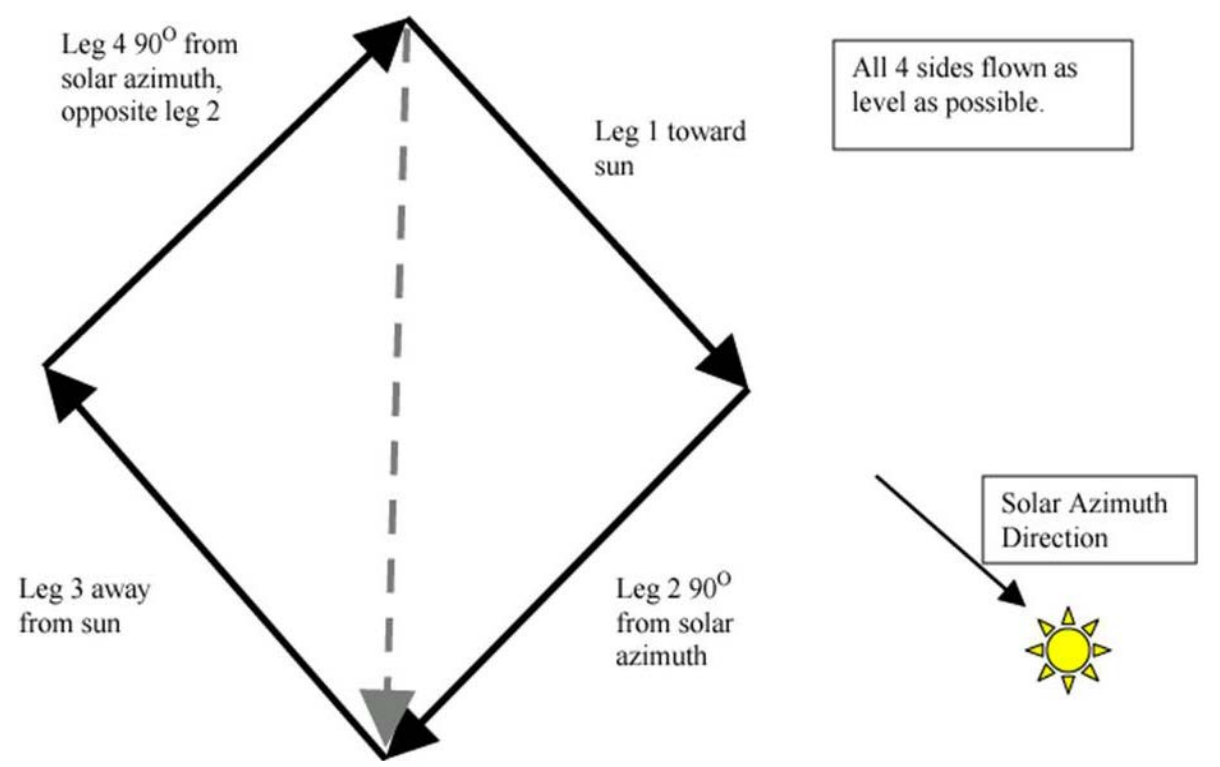

Figure A.2. Radiometer characterization patterns.

\section{G. Aerosol Triangles Flight Plan}

The primary goals are to characterize the spatial variability of aerosol size distribution and CCN over CF and relate the spatial variability of aerosol near CF with the temporal variability observed at the surface. The flight plan uses the same triangular patterns as in the standard cloud sampling pattern (Plan A) with circuits at about five altitudes:

1. Climb to $6500 \mathrm{ft}$ and descend ( 250-300 ft per minute [fpm]) to the SGP site.

2. Execute a triangle at $500 \mathrm{ft}$ AGL.

3. Spiral at $300 \mathrm{fpm}$ from $500 \mathrm{ft}$ AGL to $6500 \mathrm{ft}$.

4. Execute triangles at $6500 \mathrm{ft}$ and at two or three lower levels (preferably where there are aerosol layers).

5. After the last leg, go down to $500 \mathrm{ft}$ AGL over the SGP site and spiral up to $6500 \mathrm{ft}$.

6. Once at altitude, do slant descent heading back to Guthrie.

\section{H. Aerosol Long-Leg Variability Characterization Flight Plan}

Characterizes the aerosol variability at $2400 \mathrm{ft}$ MSL (1400 ft AGL) for legs downwind from the CF (100, 50, and 25 nautical miles [nm]):

1. Drop to $1400 \mathrm{ft} / 500 \mathrm{AGL}$ and do a slant climb to $6000 \mathrm{ft}$, then back to $2400 \mathrm{ft}$ MSL.

2. Fly to point $100 \mathrm{~nm}$ downwind of CF.

3. Long leg, inbound, $100 \mathrm{~nm}$, reevaluate wind (RW). 
4. Half-long leg, outbound, $50 \mathrm{~nm}$.

5. Half-long leg, inbound, $50 \mathrm{~nm}$, RW.

6. Quarter-long leg, outbound $25 \mathrm{~nm}$.

7. Quarter-long leg, inbound, $25 \mathrm{~nm}, \mathrm{RW}$.

8. Long-leg, outbound, $100 \mathrm{~nm}$.

9. Drop to $1400 \mathrm{ft} / 500 \mathrm{AGL}$ and do a slant climb to $6000 \mathrm{ft}$.

10. Fly home. 


\section{Appendix B EOS Satellite Overpasses During RACORO}




\section{EOS Satellite Overpasses During RACORO}

(Times in GMT)

\begin{tabular}{|c|c|c|c|c|c|c|c|}
\hline Date & Flight Mission & Departure & Return & Hours & Terra & Aqua & Comments \\
\hline $1 / 22$ & Test flight for aerosol instrument characterization & 19:38 & $21: 08$ & 1.5 & & $20: 01$ & \\
\hline $1 / 24$ & Test flight for radiometer characterization & $18: 20$ & $20: 25$ & 2.1 & & 19:49 & \\
\hline $2 / 06$ & Test flight for cloud probe characterization & $16: 50$ & $18: 31$ & 1.7 & $17: 38$ & & \\
\hline $2 / 08$ & Cloud triangles at SGP & $18: 12$ & $21: 51$ & 3.7 & & & No satellite overpass \\
\hline $2 / 17$ & Cloud triangles at SGP & $16: 18$ & $18: 58$ & 2.7 & $17: 20$ & & MISR at 17:15 \\
\hline $2 / 26$ & Cloud sampling east of Guthrie & $16: 07$ & $18: 00$ & 1.9 & 17:14 & & \\
\hline $3 / 01$ & Aerosol triangles at SGP & 15:31 & 19:57 & 4.4 & $17: 44$ & 19:24 & \\
\hline $3 / 04$ & Aerosol triangles at SGP & $14: 49$ & 19:15 & 4.4 & & & No satellite overpass \\
\hline $3 / 15$ & Turbulence at SGP \& Radiometer tilt characterization & 17:57 & $22: 57$ & 5.0 & & 19:36 & Terra at 17:56, just before takeoff \\
\hline $3 / 17$ & Turbulence at SGP \& Radiometer tilt characterization & 17:57 & $22: 48$ & 4.9 & & 19:24 & \\
\hline $3 / 18$ & Surface albedo at SGP & $18: 27$ & $21: 07$ & 2.7 & & 20:07 & \\
\hline $3 / 20$ & Cloud triangles at SGP & $12: 00$ & $16: 51$ & 4.9 & & & No satellite overpass \\
\hline $3 / 24$ & Surface albedo \& Turbulence at SGP & $17: 16$ & $22: 04$ & 4.8 & $17: 50$ & 19:30 & \\
\hline $3 / 30$ & Clear-sky triangles at SGP \& Cloud triangles east of SGP & 19:27 & $23: 42$ & 4.3 & & 19:36 & \\
\hline $4 / 03$ & Surface albedo \& Turbulence at SGP & $18: 30$ & 23:51 & 5.4 & & 20:07 & \\
\hline $4 / 07 a$ & Surface albedo \& Turbulence at SGP & $14: 00$ & 18:05 & 4.1 & & & No satellite overpass \\
\hline $4 / 07 \mathrm{~b}$ & Surface albedo \& Turbulence at SGP & 19:19 & $23: 17$ & 4.0 & & 19:42 & \\
\hline $4 / 10$ & Cloud triangles southeast of Guthrie & $12: 10$ & $16: 19$ & 4.2 & & & No satellite overpass \\
\hline $4 / 14$ & Surface albedo \& Turbulence at SGP & $15: 25$ & $20: 35$ & 5.2 & & 19:48 & \\
\hline $4 / 16$ & Cloud triangles at SGP & $16: 58$ & 21:11 & 4.2 & 17:57 & 19:36 & \\
\hline $4 / 19$ & Cloud triangles at SGP & $14: 34$ & 19:00 & 4.4 & & & No satellite overpass \\
\hline $4 / 20$ & Aerosol long-leg variability characterization at SGP & 17:54 & $22: 19$ & 4.4 & & & No satellite overpass \\
\hline $4 / 21$ & Surface albedo \& Turbulence at SGP & 18:03 & $23: 10$ & 5.1 & & 19:54 & \\
\hline $4 / 24$ & Cloud triangles at SGP & 20:02 & 00:19 & 4.3 & & & No satellite overpass \\
\hline $4 / 27$ & Cloud missed approaches Ponca-Perry & 19:44 & $00: 41$ & 5.0 & & & No satellite overpass \\
\hline $4 / 28$ & Cloud missed approaches Ponca-Perry & 19:18 & $00: 16$ & 5.0 & & 20:00 & \\
\hline $5 / 06$ & Cloud missed approaches Ponca-Perry \& Cloud triangles at SGP & $16: 21$ & $20: 43$ & 4.4 & $17: 32$ & & MISR Local mode at 17:27 \\
\hline $5 / 07$ & Cloud triangles at SGP & 18:11 & $22: 53$ & 4.7 & & 19:54 & \\
\hline $5 / 08$ & Cloud out and backs at SGP & 15:16 & $19: 10$ & 3.9 & $17: 20$ & & MISR at $17: 15$ \\
\hline $5 / 13$ & Surface albedo \& Cloud out and backs at SGP & 15:31 & $19: 27$ & 3.9 & $17: 39$ & 19:17 & \\
\hline $5 / 16$ & Turbulence at SGP & 17:00 & $22: 19$ & 5.3 & & 19:47 & \\
\hline $5 / 17$ & Radiometer tilt characterization away from SGP & $16: 10$ & $21: 05$ & 4.9 & 17:14 & & \\
\hline $5 / 18$ & Surface albedo \& Turbulence at SGP & $12: 27$ & $17: 36$ & 5.2 & & & No satellite overpass \\
\hline $5 / 19$ & Radiometer tilt characterization away from SGP & $12: 32$ & $17: 33$ & 5.0 & 17:02 & & \\
\hline $5 / 22$ & Cloud triangles at SGP & $15: 25$ & 19:52 & 4.5 & $17: 33$ & & MISR Local Mode at 17:27 \\
\hline $5 / 23$ & Cloud triangles at SGP & 14:23 & $19: 15$ & 4.9 & & & No satellite overpass \\
\hline $5 / 24$ & Cloud triangles at SGP & $15: 26$ & 19:50 & 4.4 & $17: 20$ & & MISR at 17:15 \\
\hline $5 / 26$ & Cloud triangles at SGP & 16:54 & $21: 14$ & 4.3 & 17:08 & & \\
\hline $5 / 27$ & Cloud missed approaches Ponca-Perry \& Cloud triangles at SGP & $17: 56$ & $21: 43$ & 3.8 & & 19:29 & Terra at 17:51, just before takeoff \\
\hline $5 / 30$ & Aerosol long-leg variability \& Turbulence at SGP & 16:57 & $22: 27$ & 5.5 & & 19:59 & \\
\hline $5 / 31$ & Aerosol long-leg variability \& Turbulence at SGP & 16:57 & $22: 06$ & 5.2 & $17: 26$ & & MISR Local Mode at 17:21 \\
\hline $6 / 01$ & Aerosol long-leg variability \& Turbulence at SGP & $16: 55$ & $21: 53$ & 5.0 & & 19:47 & \\
\hline $6 / 03$ & Cloud triangles at SGP & 19:07 & $23: 34$ & 4.5 & & 19:35 & \\
\hline $6 / 04$ & Surface albedo \& Turbulence at SGP & $15: 16$ & $20: 02$ & 4.8 & 17:02 & & \\
\hline $6 / 07$ & Aerosol triangles at SGP & $17: 10$ & $22: 53$ & 5.7 & $17: 33$ & & MISR Local Mode at 17:27 \\
\hline $6 / 08$ & Cloud triangles at SGP & 16:17 & $22: 03$ & 5.8 & & 19:53 & \\
\hline $6 / 09$ & Cloud triangles at SGP & $16: 26$ & $20: 14$ & 3.8 & $17: 20$ & & MISR at 17:15 \\
\hline $6 / 11$ & Cloud triangles at SGP & $16: 59$ & $21: 12$ & 4.2 & $17: 08$ & & \\
\hline $6 / 12$ & Cloud triangles at SGP & 18:01 & $21: 27$ & 3.4 & & 19:28 & \\
\hline $6 / 15$ & Surface albedo \& Turbulence at SGP \& Cloud northeast of SGP & 16:01 & $20: 58$ & 5.0 & & 19:59 & \\
\hline $6 / 17$ & Aerosol triangles for CALIPSO overpass at SGP & 16:57 & $22: 29$ & 5.5 & & 19:47 & CALIPSO overpass \\
\hline $6 / 18$ & Cloud triangles at SGP & $18: 15$ & $23: 15$ & 5.0 & & & No satellite overpass \\
\hline $6 / 19$ & Cloud triangles at SGP \& Cloud out and backs east of SGP & 19:31 & $23: 47$ & 4.3 & & 19:34 & \\
\hline $6 / 20$ & Cloud triangles at SGP & $17: 25$ & $22: 26$ & 5.0 & & $20: 17$ & \\
\hline $6 / 23$ & Cloud triangles east of SGP & 19:00 & $23: 26$ & 4.4 & & & No satellite overpass \\
\hline $6 / 24$ & Cloud out and backs for CALIPSO overpass south of SGP & 19:00 & $23: 42$ & 4.7 & & 19:52 & CALIPSO overpass \\
\hline $6 / 26$ & Aerosol out + backs for CALIPSO \& Turbulence, Cloud south of SGP & $18: 42$ & $23: 33$ & 4.9 & & 19:40 & CALIPSO overpass \\
\hline $6 / 28$ & Surface albedo \& Turbulence at SGP & 15:58 & $20: 59$ & 5.0 & 17:51 & 19:28 & \\
\hline $6 / 29$ & Turbulence at SGP & 18:00 & $22: 46$ & 4.8 & & $20: 11$ & \\
\hline
\end{tabular}




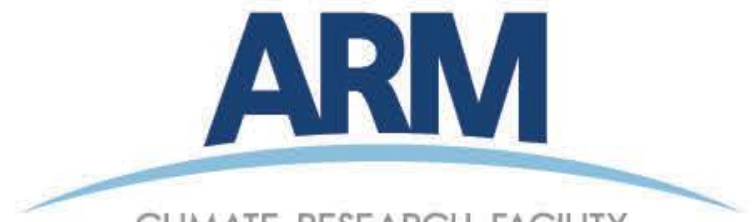

CLIMATE RESEARCH FACILITY

www.arm.gov

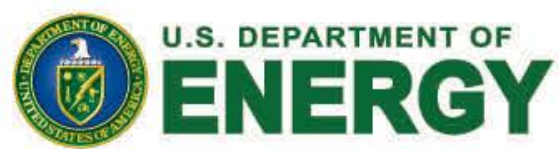

Office of Science 